\title{
Flavobacterial response to organic pollution
}

\author{
Andrew Bissett ${ }^{1,2,3, *}$, John P. Bowman ${ }^{2}$, Chris M. Burke $^{1}$ \\ ${ }^{1}$ School of Aquaculture, Tasmanian Aquaculture and Fisheries Institute, University of Tasmania and Aquafin CRC, \\ Launceston, Tasmania 7250, Australia \\ ${ }^{2}$ School of Agricultural Science, University of Tasmania, Hobart, Tasmania 7001, Australia \\ ${ }^{3}$ Present address: Max Planck Institute for Marine Microbiology, Celsiusstrasse 1, 28359 Bremen, Germany
}

\begin{abstract}
Bacteria of the Cytophaga-Flavobacterium-Bacteroides (CFB) group (phylum Bacteroidetes), in particular members of the class Flavobacteria, are among the most prominent heterotrophic organisms in marine pelagic systems. They have also previously been found to be important in the initial biopolymer degradation of sedimentary organic matter. The Flavobacteria community was analysed in inshore, marine sediments subject to regular inputs of highly labile organic carbon in order to understand the importance of this group in carbon degradation. We used denaturing gradient gel electrophoresis and real-time PCR in a statistically robust manner, over 2 consecutive years, to demonstrate that the number of Flavobacteria in the sediment increased and community composition shifted with organic loading. Further community shifts occurred after cessation of organic loading, and population numbers also decreased. Flavobacteria appear to be important in the initial responses of the sediment microbial community to organic loading, regardless of sediment type, but flavobacterial composition was not predictable. The highly dynamic nature and large diversity (functional redundancy) of the Flavobacteria in these sediments may contribute to this unpredictable response.
\end{abstract}

KEY WORDS: Flavobacteria · Organic pollution · Degradation · Community composition Resale or republication not permitted without written consent of the publisher

\section{INTRODUCTION}

Organic enrichment/pollution is widely encountered in marine systems and is increasing as population settlement and marine industries grow. As awareness of anthropogenic organic inputs has grown, their impacts on coastal zones (and in particular estuarine zones) have become increasingly important in discussions regarding environmental management.

Microbial communities play a pivotal role in organic carbon mineralisation in coastal ecosystems and are of fundamental importance to system function by determining nutrient cycling, decomposition and energy flow (Zak et al. 1994, Wardle \& Giller 1996). An understanding of microbial responses to anthropogenic input is necessary to ensure the sustainability of coastal zones. For example, organic carbon enrichment may lead to increased microbial production, oxygen depletion and production of toxic metabolites. Hypoxia/ anoxia may lead to the replacement of aerobic species with microaerophilic and anaerobic species and as a result alter ecosystem functions such as nutrient cycling (Paerl 1998). Overall, microbial activity in marine sediments is determined by geographic position, sedimentation rate, quality of the sedimenting material, temperature and sediment chemical conditions, but it is well established that sediment communities respond rapidly to altered nutrient input (Battersby \& Brown 1982, Paerl 1998, Cloern 2001, Paerl et al. 2003).

The exact nature of community changes and the factors that cause them are often difficult to elucidate, particularly as they can involve a cascade of events. For example, increased sedimentation may increase nutrient supply, but this may be both episodic and spatially heterogeneous. Rapid generation times and a high level of functional redundancy in micro-organisms, together with the stochastic nature of environ- 
mental change, further complicate interpretation of community succession. Consequently, in continually changing systems, a particular niche may not be filled by the same organism every time it arises, but the organism that fills it may have the same function. All of this underlines the importance of a strong sampling design, along with sound data analysis, when trying to elucidate microbial community changes under conditions relevant to the extant populations and their environment.

The phylum Bacteroidetes, previously known as the Cytophaga-Flavobacterium-Bacteroidetes (CFB) phylum, is a broad group encompassing members exhibiting a range of physiological capabilities as well as being adapted to many environmental conditions (Reichenbach \& Dworkin 1991, Weller et al. 2000, Bernardet \& Nakagawa 2006). Of interest herein are the members of the Bacteroidetes that are common in marine environments and may therefore play a role in organic matter degradation in marine sediments. Bacteroidetes are strongly associated with the marine water column and marine aggregates (Cottrell \& Kirchman 2000, Abell \& Bowman 2005a,b), but fewer studies have examined them in sediment communities (e.g. Llobet-Brossa et al. 1998, Ravenschlag et al. 2001). The Bacteroidetes were also thought to be mainly important in aerobic environments, but the addition of complex organic substrates to anaerobic sediments resulted in the growth of members of this group (Rosselló-Mora et al. 1999, Cytryn et al. 2003). Ravenschlag et al. (2001) have also demonstrated high numbers of Cytophaga-Flavobacterium cells in both aerobic and anaerobic marine sediments. Because of their hydrolytic capabilities, the Bacteroidetes may be important as the initial degraders of organic matter, particularly the high molecular weight fraction, such as proteins, polysaccharides and algal debris (Cottrell \& Kirchman 2000, Abell \& Bowman 2005a, Covert \& Moran 2001). Biopolymers are the major component of fresh organic matter, and the presence of Bacteroidetes may therefore be integral to sediment recovery from organic pollution. However, the aforementioned studies on the effects of added organic carbon were conducted in atmosphere-controlled bags (Rosselló-Mora et al. 1999) or in a bioreactor (Cytryn et al. 2003). Because the in situ sediment structure was lost, these studies investigated potential activity. Thus, the actual responses of the Bacteroidetes to organic pollution in marine sediments have not been directly investigated.

Many of the important marine Bacteroidetes fall into the class Flavobacteria and are able to be detected by the primer 558f (Weller et al. 2000, Abell \& Bowman $2005 a, b)$. This primer is highly specific to members of the class Flavobacteria (Abell \& Bowman 2005b), specifically the family Flavobacteriaceae, the clone Agg58 group and the family Cryomorphaceae. Indeed, a parallel clone library survey of total bacterial diversity in the organically loaded sediments investigated herein observed that the number of clones affiliated with the Bacteroidetes increased with organic loading, and that 558f successfully targeted much of the sediment Bacteroidetes community of these sites (Bissett et al. 2006). Although use of this single primer set necessarily underestimates the true Bacteroidetes community, it does allow a reasonable approximation of potentially important members of the marine sediment community in these sediments. The use of the term Flavobacteria herein therefore refers specifically to organisms detectable by the primer 558f, primarily members of the class Flavobacteria.

Although sediment organisms such as invertebrates often respond in a predictable manner to organic loading (Pearson \& Rosenberg 1978), the dynamic nature of complex bacterial communities complicates the acquisition of data describing the community responses to perturbation. To ensure the statistical validity of the interpretation of bacterial community changes, techniques that allow adequate replication (both spatially and temporally) are necessary. One such technique is denaturing gradient gel electrophoresis (DGGE), which like all fingerprinting techniques has both advantages and disadvantages. Despite the fact that DGGE only samples the most abundant community members, it does allow for phylotypes (bands) to be identified and also for the throughput of large numbers of samples. Combined with PCR primers specific for the target group, DGGE gives reasonably high resolution when monitoring bacterial communities (Abell \& Bowman 2005b). The primers used in this study are highly specific to the class Flavobacteria (Abell \& Bowman 2005b). The specificity of the primers used in the current study increased the resolution of the DGGE technique (over that obtainable with general primers) by limiting the detectable phylotypes to Flavobacteria, which were seen as likely members of an active Bacteroidetes community (Bissett et al. 2006). Thus, we were able to investigate the temporal dynamics of the Flavobacteria community response to organic perturbation.

Salmon sea cage farms offer an excellent site for examining the effects of organic loading on sediments, as they present clearly defined point sources of high, readily metabolisable organic carbon. Commonly, salmon farms use production cycles that include a stocking phase, in which cages contain high concentrations of fish, and a fallowing phase, in which cage sites are rested after the fish have been harvested. Thus, the sediments are alternately subjected to periods of high organic input in the form of fish faeces and 
uneaten food, followed by periods of much lower input typical for the particular locale.

To our knowledge, our study is the first to investigate changes in the flavobacterial community structure in organically polluted marine sediments. We used molecular techniques to investigate the diversity and relative abundance of the Flavobacteria in marine sediments around fish farms. The flavobacterial communities at 2 fish farms were analysed over 2 production cycles comprising 9 mo of stocking and 3 mo of fallowing, to investigate the role these bacteria play in organically loaded sediments.

\section{MATERIALS AND METHODS}

Sample collection. Samples were collected as described by Bissett et al. (2006). Briefly, 2 salmon farms, exhibiting different environmental conditions, were investigated. They were located on the Tasman Peninsula ( $43^{\circ} 6^{\prime} \mathrm{S}, 147^{\circ} 45^{\prime} \mathrm{E}$; Farm 1 ) and the D'Entre-

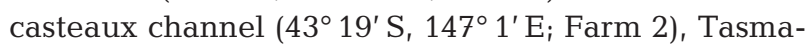
nia, Australia. Farm 1 was in a coastal location, and depth ranged from 15 to $20 \mathrm{~m}$. It was exposed to westerly and south-westerly winds and was heavily influenced by wave and swell action. Sediments at Farm 1 were predominantly fine sands, with a low percentage of silt-clays. Carbon content was low ( $0.2 \%$; Macleod et al. 2004b). Farm 2 was situated in deeper water (35 to $40 \mathrm{~m}$ ) and was also primarily marine, although it was riverine-influenced and was protected from most wave action and ocean swells. Sediments were predominantly silt-clays, and carbon content $(\sim 4 \%)$ was much higher at this location than at Farm 1.

At both farms, 6 sediment cores were randomly taken from 2 cage sites $(2 \times 3)$ and 2 reference sites $(2$ $\times 3$ ) situated $150 \mathrm{~m}$ from the edge of the study cages, and perpendicular to the predominant water flow. Samples were taken 2 mo into the stocking period (T2), at the end of the 9 mo stocking period (T9) and at the end of the 3 mo fallowing period (T12). This was then repeated the following year. Cage sites are referred to as 'enriched' and reference sites as 'unenriched'. Unenriched sediments exhibited the same depth and particle size distribution as their respective enriched sites. As a result of a farm management error, 1 enriched site at Farm 1 received 4.5 mo fallow time rather than 3 mo. Thus for the second production cycle at Farm 1, enriched sites and their respective unenriched control sites were considered separately (i.e. $\mathrm{n}=3$, rather than $\mathrm{n}=6$ for this period). Sediment cores were collected using polyethylene tubes (150 mm diameter) and a Craib corer (see www.duncanandassociates.co.uk). Cores were all at least $100 \mathrm{~mm}$ deep and showed no signs of physi- cal disturbance. After collection, cores were stored in an ice cooler filled with ambient water for transfer to the laboratory.

DNA extraction and purification. DNA was extracted from the top $1 \mathrm{~cm}$ of sediment cores as described by Bissett et al. (2006). Briefly, samples of sediment $(0.5 \mathrm{~g})$ were added to $2 \mathrm{ml}$ screw-cap tubes containing $0.5 \mathrm{~g}$ of $0.1 \mathrm{~mm}$ zirconium-silica beads, $700 \mu \mathrm{l}$ of $120 \mathrm{mM}$ sodium phosphate (pH 8.0), $1 \% \mathrm{w} / \mathrm{v}$ (weight in volume) acid-washed polyvinylpolypyrrolidone, $500 \mathrm{ml}$ of Tris-equilibrated phenol and $50 \mu \mathrm{l}$ of $20 \% \mathrm{w} / \mathrm{v}$ sodium dodecyl sulphate. The samples were bead beaten (Mikrodismembrator U; B. Braun Biotech International) at $3800 \mathrm{rpm}$ for $3 \times 10 \mathrm{~s}$, with $30 \mathrm{~s}$ on ice between beatings. They were then centrifuged at $20800 \times g$ for $2 \mathrm{~min}$, and supernatants were stored on ice. The sediment pellet was then resuspended in $700 \mu \mathrm{l}$ sodium phosphate buffer and bead beaten at $3800 \mathrm{rpm}$ for $20 \mathrm{~s}$ and centrifuged again. Supernatants were pooled. Nucleic acids were precipitated with ethanol and resuspended in $50 \mu \mathrm{l}$ of Milli-Q water. Extractions were then purified using the Prep-Agene DNA purification system (Bio-Rad Laboratories), according to the manufacturer's instructions. Final extractions were stored at $-20^{\circ} \mathrm{C}$

Polymerase chain reaction (PCR). Fragments of the 16S rRNA gene were enzymatically amplified using a 1650 Air Thermo-Cycler (Idaho Technology) with the Flavobacteria-specific primers 558-f (ATT GGG TTT AAA GGG TCC; Abell \& Bowman 2005b) and 1392RC (CGC CCG CCG CGC CCC GCG CCC GGC CCG CCG CCC CCG CCC CAC GGG CGG TGT GTA C; Ferris et al. 1996). We checked the specificity of probe 558f against the RDP 16S rRNA collection using Probe Match (http://rdp.cme.msu.edu/probematch/search.jsp) and against the SILVA/ARB database using Probe Check (http://131.130.66.200/cgi-bin/probecheck/ con tent.pl?id=home). The probe showed good specificity to the Bacteroidetes, giving only 12 perfect matches outside this group (almost exclusively within the Archaea). Within the Bacteroidetes, the probe covers $84 \%$ of the class Flavobacteria (www.microbialecology.net/probebase/list.asp?list=probes), and has several mismatches within the families Bacteroidaceae, Flexibacteraceae, Flammeovirgaceae, Sphingobacteria and Crenotrichaceae. The probe is highly specific for important marine flavobacterial groups (Abell \& Bowman 2005b). Reactions were performed using the Advantage 2 Polymerase Kit (Clontech) in accordance with the manufacturer's recommendations: reactions of $50 \mu \mathrm{l}$ contained 10× Advantage Taq PCR 2 Reaction Buffer, $1 \mu$ l of Advantage PCR 2 Taq DNA

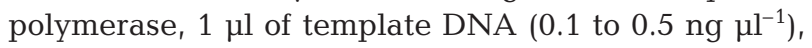
$10 \mathrm{pmol}$ of each primer, and $1.25 \mathrm{mM}$ of each deoxynucleoside triphosphate. Thermal cycling was carried out 
with an initial denaturation step of $95^{\circ} \mathrm{C}$ for $4 \mathrm{~min}$ followed by 19 cycles of denaturation at $95^{\circ} \mathrm{C}$ for $1 \mathrm{~min}$, annealing at $64^{\circ} \mathrm{C}$ for $1 \mathrm{~min}$ (decreasing by $-0.5^{\circ} \mathrm{C}$ every cycle), and elongation at $72^{\circ} \mathrm{C}$ for 2 min and 10 cycles of denaturation at $95^{\circ} \mathrm{C}$ for $1 \mathrm{~min}$, annealing at $54^{\circ} \mathrm{C}$ for $1 \mathrm{~min}$, and elongation at $72^{\circ} \mathrm{C}$ for $2 \mathrm{~min}$; cycling was completed by a final elongation step of $72^{\circ} \mathrm{C}$ for $4 \mathrm{~min}$. Amplification products were checked visually by agarose (1\%) gel electrophoresis.

Denaturing gradient gel electrophoresis (DGGE). DGGE was performed using the D-code Universal Mutation Detection System (Bio-Rad Laboratories) according to the method for perpendicular gels in the Bio-Rad manual. Samples were initially analysed with a 20 to $80 \%$ denaturing gradient using an $8 \%$ acrylamide gel. Samples were then re-run using a gradient of 20 to $50 \%$ for better band separation. Gels were run at $80 \mathrm{~V}$, $60^{\circ} \mathrm{C}$ for $16 \mathrm{~h}$, cooled and stained for 20 min using $10 \mu \mathrm{l}$ of $10000 \times$ SYBR-gold nucleic acid stain (Molecular Probes) in $100 \mathrm{ml}$ Tris-acetate EDTA (TAE) buffer (40 mM Tris-acetate; 1 mM disodium EDTA; pH 8). Gels were imaged using a UV transilluminator, and digital images were captured on a Kodak DC60 digital camera fitted with a deep yellow \#15 filter (Tiffen). Bands were excised using a sterile scalpel blade, placed in a microcentrifuge tube and washed with $200 \mu$ l of sterile Milli$\mathrm{Q}$ water for 30 min to avoid external DNA contamination. DNA was then eluted from excised bands by soaking in $200 \mu \mathrm{l}$ of STE buffer overnight at $37^{\circ} \mathrm{C}$.

Analysis of DGGE fingerprints. Individual bands were defined by a visually discernable signal above the gel background. Images of DGGE gels were analysed by assigning numbers to each of the bands present on the gel and then scoring each sample to define presence or absence of each band. Lanes/ samples with no bands were excluded from the analysis. Scoring of gel banding patterns resulted in a binary matrix containing presence/absence data for each set of samples. Statistical analyses were then performed on this matrix.

PCR re-amplification of DGGE band DNA. Duplicate DGGE bands were extracted from the same vertical positions but in different lanes from the DGGE gels. This was done to confirm that bands at the same position on the gels could be considered to be the same phylotype. Band eluent $(1 \mu \mathrm{l})$ was re-amplified using primers 558f and 1392r with the Hotstart PCR Kit (Qiagen). PCR was performed with a $15 \mathrm{~min}, 95^{\circ} \mathrm{C}$ 'hotstart' step, followed by 25 cycles of $95^{\circ} \mathrm{C}$ for $1 \mathrm{~min}, 55^{\circ} \mathrm{C}$ for $1 \mathrm{~min}$ and $72^{\circ} \mathrm{C}$ for $1 \mathrm{~min}$, with a final $4 \mathrm{~min}$ step at $72^{\circ} \mathrm{C}$. Re-amplified DNA product was then purified using the Prep-A-Gene ${ }^{\circledR}$ DNA purification system prior to sequencing.

Sequencing and phylogenetic analysis. Direct sequencing of PCR products amplified from DGGE bands was carried out using the CEQ Dye Terminator Cycle Sequencing (DTCS) with Quick Start Kit (Beckman-Coulter). Reactions were carried out using a modification of the manufacturer's protocol; reactions were performed in $10 \mu \mathrm{l}$ volumes using $2 \mu \mathrm{l}$ of DTCS Quick Start Master Mix, $1 \mu$ l of primer $\left(1.6 \mathrm{pmol} \mathrm{\mu l}^{-1}\right)$, and reactions were resuspended in $30 \mu \mathrm{l}$ of Sample Loading Solution after ethanol precipitation. Sequencing reactions were analysed using a Beckman CEQ2000 automated DNA sequencer, and electrophoretograms were manually checked and sequence data imported into a database using the BioEdit program (Hall 1999). Sequences were compared to sequences in the GenBank database (www.ncbi.nlm.nih.gov/blast) using the Basic Local Area Search Tool (BLASTn; Altschul et al. 1997). Sequences from this study were then aligned to reference sequences obtained from GenBank, using the BioEdit program and ClustalW (Thompson et al. 1994).

The aligned DGGE band sequences were then imported into and analysed using the software ARB (Ludwig et al. 1998). Phylogenetic trees were calculated using maximum parsimony, based on long 16S rRNA sequences (more than $1300 \mathrm{bp}$ ) and the latest SILVA alignment (Pruesse et al. 2007). The short DGGE band sequences were then inserted into the pre-established tree, using the parsimony ARB tool, and maintaining the overall tree topology without changes.

Sequences from this study have been deposited in GenBank under accession numbers DQ297146 to DQ297171.

Real-time PCR. Real-time PCR was performed on sediment samples using the primers specific for Flavobacteria described above. Standard curves were generated using Flavobacteria sequence PCR fragments (from Gelidibacter algens and Cryomorpha ignava), mixed 1:1 to the desired concentration. DNA concentrations obtained from standard curves were converted to fragment copy number, which was then used as a proxy for Flavobacteria cell number. Conversion to absolute cell number was not possible because it has not been shown that all Bacteroidetes have only one rrn operon.

Primers used for amplification and detection of class Flavobacteria 16S rRNA genes were 558f (ATTGGG TTTAAAGGGTCC) and 907r (CCG TCAATTCCT TTGAGTTT; Lane 1991). Total bacterial 16S rRNA gene abundances were estimated with primers $519 \mathrm{f}$ (CAG CMG CCG CGG TAA TAC) and 907r. PCR reactions were performed in $20 \mu \mathrm{l}$ volumes using single $100 \mu \mathrm{l}$ strip tubes (Corbett Research). PCR reactions were performed using the Rotor-Gene thermocycler (Corbett Research), and data analysed using the RotorGene software (v.5.0). Reactions contained $2 \mu \mathrm{l}$ of $10 \times$ 
Advantage Taq PCR 2 Reaction Buffer (Clontech), $0.4 \mu \mathrm{l}$ of Advantage PCR 2 Taq DNA polymerase (Clon-

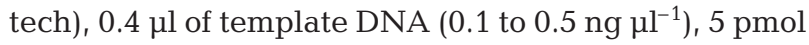
of each primer, $1.25 \mathrm{mM}$ of each deoxynucleoside triphosphate and SYBR green nucleic acid stain (Molecular Probes) at a final concentration of 1:40 000. Assays were performed using a 4 step thermocycling program consisting of an initial $5 \mathrm{~min} 95^{\circ} \mathrm{C}$ incubation followed by 35 cycles of a denaturation step of $30 \mathrm{~s}$ at $95^{\circ} \mathrm{C}$, annealing of primers for $30 \mathrm{~s}$ at $55^{\circ} \mathrm{C}$, elongation for $30 \mathrm{~s}$ at $72^{\circ} \mathrm{C}$ with fluorescent acquisition, and a further fluorescent acquisition step at $80^{\circ} \mathrm{C}$. The temperature at which fluorescence acquisition occurred was determined by examination of the melting profile of a number of samples, and performed at a temperature at which all primer dimers had melted, but the specific product had not $\left(80^{\circ} \mathrm{C}\right)$. Quantitative PCR reactions were treated as valid only when standard curves produced $\mathrm{R}^{2}>0.99$ and reaction efficiencies were $>0.85$. When these conditions were not met, analyses were re-run.

All real-time PCR products were examined using agarose gel electrophoresis to ensure products corresponded to the correct size, and to ensure the absence of non-specific product. Samples were run in duplicate and the analysis was repeated if variance exceeded $10 \%$.

Univariate statistical analysis. Factorial analysis of variance (ANOVA) was used to test for the effect of farm (2 levels) and time (3 levels) on Flavobacteria DNA concentrations. Homogeneity of variances was checked visually by examining residual plots. Data that did not meet this assumption of ANOVA were log transformed. Significant factors were then compared using Tukey's HSD. All univariate statistical tests were tested at $\alpha=0.05$. The statistical software SPSS v.10 was used to perform these tests.

Multivariate analysis. The mutlivariate techniques described below were employed to test for the effect of farm (2 levels) and time (3 levels) on Flavobacteria community changes. The multivariate approach used in this study was similar to that advocated by Clarke \& Warwick (2001), using the following steps: (1) A visual representation of the community by hierarchical clustering, canonical analysis of principle coordinates (CAP) (Legendre \& Anderson 1999, Anderson 2003a) and non-metric multidimensional scaling (nMDS). (2) Discrimination of the samples using non-parametric multivariate analysis of variance (NPMANOVA) to test for significant interaction terms, followed by 1-way analysis of similarity (ANOSIM) to investigate sources of significant differences if they were returned in the global test. Analyses were conducted using the software Primer 5.2.4, CAP (Anderson 2003a), NPMANOVA (Anderson 2003c, for balanced designs), (Anderson 2003d) and DISTLM v.2 (Anderson 2003b, for unbalanced designs). All multivariate statistical tests were tested at $\alpha=0.05$, but where the number of permutations was so low that this could never be achieved, the number of permutations possible are also included in the results.

\section{RESULTS}

\section{Enriched sediment conditions}

Sediments beneath fish farms exhibited conditions typical for organically enriched sediments. That is, with organic loading, oxygen penetration decreased from $\sim 4$ to $<1 \mathrm{~mm}$ and diffusive oxygen flux increased significantly (Bissett et al. 2007). Sediment sulphide and ammonia concentrations also increased markedly (Macleod et al. 2004b).

\section{DGGE profiles}

\section{Farm 1, Year 1}

For the first $12 \mathrm{mo}$, the flavobacterial community changed considerably as shown in the nMDS plot (Fig. 1A). Ordination plots are used to reduce the complexity of multi-dimensional data. They represent the data in 2-dimensions, where the closer (farther apart) 2 sample points are, the more similar (different) they are. How well the data are represented in the reduced dimensions is indicated by the stress level, which in the nMDS plots is a measure of how well the multidimensional data are represented in the 2 dimensions presented: stress $<0.05$ represents an excellent representation, $<0.1$ is a good representation, $<0.2$ is still a potentially useful lower dimensional representation, and at $>0.3$, the data points are close to being arbitrarily placed (Clarke \& Warwick 2001). Furthermore, the flavobacterial community responded to several factors, as revealed by a significant interaction $\left(F_{2,27}=15, \mathrm{p}=\right.$ 0.001) between treatment and time effects on Flavobacteria community composition. A significant interaction term implies that 2 or more factors interact to affect the samples, and it is therefore not possible to interpret the results of 1 factor without making reference to the other. The subsequent 1-way ANOSIM for pairs of planned comparisons of treatment/time combinations (Table 1) showed that Flavobacteria communities at unenriched sites were different from those at enriched sites at all times, as seen by the high R-values. The R-value is a measure of the degree of separation between samples. It is not dependent on $\mathrm{N}$ (as the significance test is) and is calculated from the full multi-dimensional data set. A high R-value (close to 1) 


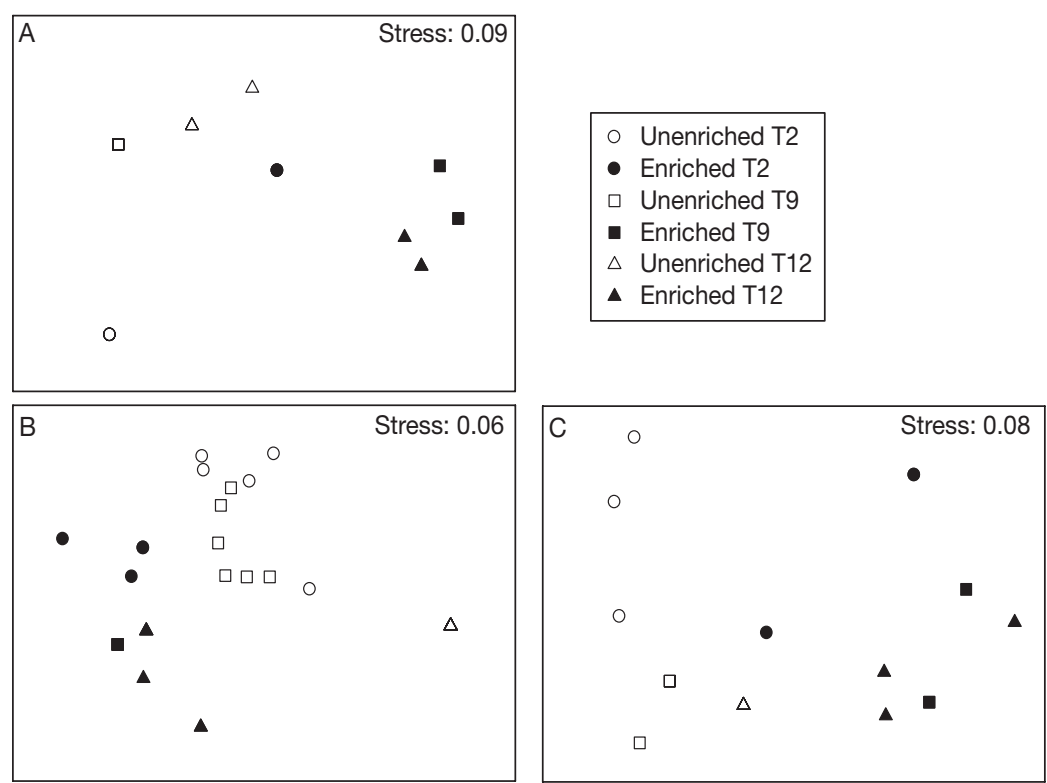

Fig. 1. nMDS plots showing Flavobacteria community shifts at Farm 1 during the 24 mo study. (A) Enriched and unenriched sites during production cycle 1, $\mathrm{n}=6$; (B) Enriched 1/Unenriched 1 during production cycle 2, $\mathrm{n}=3$; and (C) Enriched 2/Unenriched 2 during production cycle $2, \mathrm{n}=3$. (A) T2 $=2 \mathrm{mo}, \mathrm{T} 9=$ $9 \mathrm{mo}, \mathrm{T} 12=12 \mathrm{mo}$; (B) T2 = $12 \mathrm{mo}, \mathrm{T} 9=21 \mathrm{mo}, \mathrm{T} 12=24 \mathrm{mo}$ (C) T2 = $13.5 \mathrm{mo}$,

$$
\mathrm{T} 9=22.5 \mathrm{mo}, \mathrm{T} 12=25.5 \mathrm{mo}
$$

Table 1. ANOSIM values comparing the similarity between pairs of locations at Farm 1, production cycle 1, and at Farm 2, production cycle 2. Permutation numbers are given when there were not sufficient permutations possible to allow testing at $\mathrm{p}<0.05$. T0 $=0 \mathrm{mo}$; $2=2 \mathrm{mo}$; $9=9 \mathrm{mo}$; $12=12 \mathrm{mo}$; NA: not applicable

\begin{tabular}{|lccc|}
\hline Group & $\mathrm{R}$ & $\begin{array}{c}\text { Significance } \\
\text { level (\%) }\end{array}$ & Permutations \\
\hline Farm 1, production cycle 1 & & & \\
Unenriched T2, Enriched T2 & 0.844 & 0.8 & NA \\
Unenriched T9, Enriched T9 & 0.928 & 0.2 & NA \\
Unenriched T12, Enriched T12 & 1 & 0.2 & NA \\
Unenriched T2, Unenriched T9 & 0.403 & 3.5 & NA \\
Unenriched T9, Unenriched T12 & 1 & 0.2 & NA \\
Unenriched T2, Unenriched T12 & 0.936 & 0.2 & NA \\
Enriched T2, Enriched T9 & 1 & 0.5 & NA \\
Enriched T9, Enriched T12 & 0.567 & 0.2 & NA \\
Enriched T2, Enriched T12 & 0.905 & 0.5 & \\
Farm 2, production cycle 2 & & & 35 \\
Enriched T0, Unenriched T0 & 0.333 & 11.4 & 462 \\
Enriched T9, Unenriched T9 & 0.885 & 0.2 & 21 \\
Enriched T12, Unenriched T12 & 0.782 & 4.8 & 210 \\
Unenriched T0, Unenriched T9 & 0.833 & 0.5 & 15 \\
Unenriched T9, Unenriched T12 & 0.969 & 3.6 & 210 \\
Unenriched T0, Unenriched T12 & 1 & 6.7 & 462 \\
Enriched T0, Enriched T9 & 0.956 & 0.5 & 126 \\
Enriched T9, Enriched T12 & 0.045 & 30.1 & 1.6 \\
Enriched T0, Enriched T12 & 0.563 & & \\
\hline
\end{tabular}

indicates complete separation, whereas a low R-value (close to 0) indicates no separation. At unenriched sites, the community showed a small shift during the stocking period $(\mathrm{R}=0.403)$, followed by a major shift during the fallowing period $(\mathrm{R}=0.936)$. However, at enriched sites, the major shift occurred over the 9 mo stocking period, with no further shift (away from the T2 community) during the fallowing period, although variation between replicates did decrease (Fig. 1A).

Farm 1, Year 2

For the second 12 mo, enriched site 1/unenriched site 1 and enriched site 2/unenriched site 2 combinations were considered separately, rather than as replicates (see 'Materials and methods').

Enriched 1/Unenriched 1. Again, a significant interaction $\left(F_{2,12}=950, \mathrm{p}=\right.$ $0.001)$ between treatment and time in their effects on Flavobacteria community composition indicate the complex response of the community to both organic loading and to other effects. ANOSIM results for comparisons of pairs of treatment/time combinations showed $\mathrm{p}$-values at the lower limit $(\mathrm{p}=$ $10 \%$ ), given the small number of permutations possible for the test. However, the high R-values for these tests indicate that it is highly likely that the groups are different, despite not achieving a $p$-value $<0.05$. Fig. 2 shows a cluster diagram that aids in the interpretation of the nMDS plot for this production cycle (Fig. 1B). These groupings are more useful than the significance test in this instance, and demonstrate that at the highest level (55\% similarity) the unenriched site at the beginning of the stocking period is different from all other groups. At around $70 \%$ similarity, however, 3 groups appear to form, comprising (1) the unenriched sites at the beginning of the stocking period, (2) the enriched sites at the beginning of the stocking period and the remaining unenriched sites and (3) the enriched sites at the end of the stocking period and at the end of the trial.

Enriched 2/Unenriched 2. No significant interaction between treatment and time was detected, but both factors (treatment $F_{1,12}=22$, time $F_{2,12}=7.9$ ) significantly affected Flavobacteria community composition 


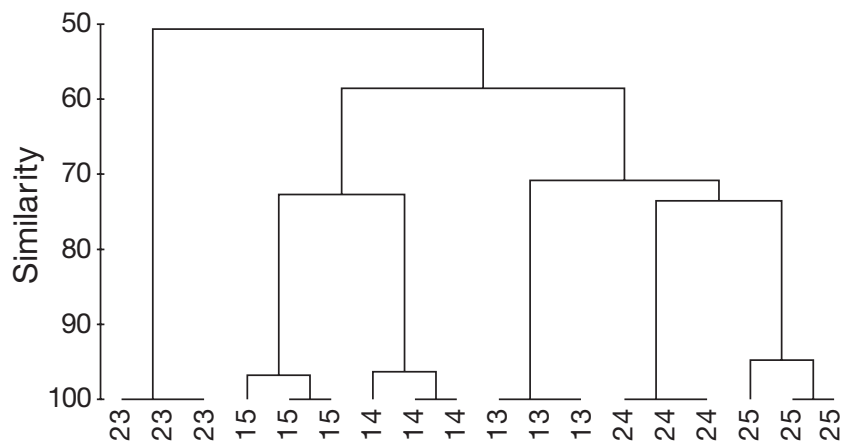

Fig. 2. Treatment time combinations from enriched site 1, unenriched site 1 over production cycle $2, \mathrm{n}=3$. Samples with a first digit of 1 denote enriched sites and those with a first digit of 2 are unenriched sites. The second digit refers to the time ( 3 = start of stocking period, $4=$ end of stocking/start of fallowing, 5 = end of fallowing)

( $p<0.001)$. Enriched site Flavobacteria communities differed from those at unenriched sites, and the trend in change over time was similar over both treatments (Fig. 1C). The nMDS results indicate that both enriched and unenriched communities shifted from those observed at the beginning of production cycle 2, but remained relatively stable throughout the stocking period.

\section{Farm 2}

Nine samples were omitted from the analysis of Flavobacteria community profiles during the first 12 mo because no bands were observed on DGGE gels. During the first 12 mo period, the Flavobacteria community was significantly different between enriched and unenriched sites $\left(F_{7,17}=35, \mathrm{p}=0.0001\right)$. Time also had a significant effect on the Flavobacteria community $\left(F_{2,17}=8.9, \mathrm{p}=0.002\right)$. ANOSIM showed that all times were different from one another, but that Flavobacteria communities did not change as much during the fallowing period as they did during the first 9 mo stocking period (Fig. 3A).

During the second 12 mo at Farm 2, 9 samples were also omitted. NPMANOVA showed a significant interaction between treatment and time $\left(F_{2,20}=3.9, \mathrm{p}=\right.$ 0.003) on Flavobacteria community dynamics. Fig. 3B shows an nMDS plot of treatment/time combinations for Flavobacteria banding patterns. The stress level of this plot (Fig. 3B) is relatively high, but its interpretation is aided by ANOSIM results for comparisons between enriched and unenriched sites at each time and between the enriched sites and the unenriched sites (Table 1). At the beginning of the second $12 \mathrm{mo}$, Flavobacteria communities at enriched and unenriched sites were not significantly different. At the end of the 9 mo stocking cycle, the Flavobacteria communities at
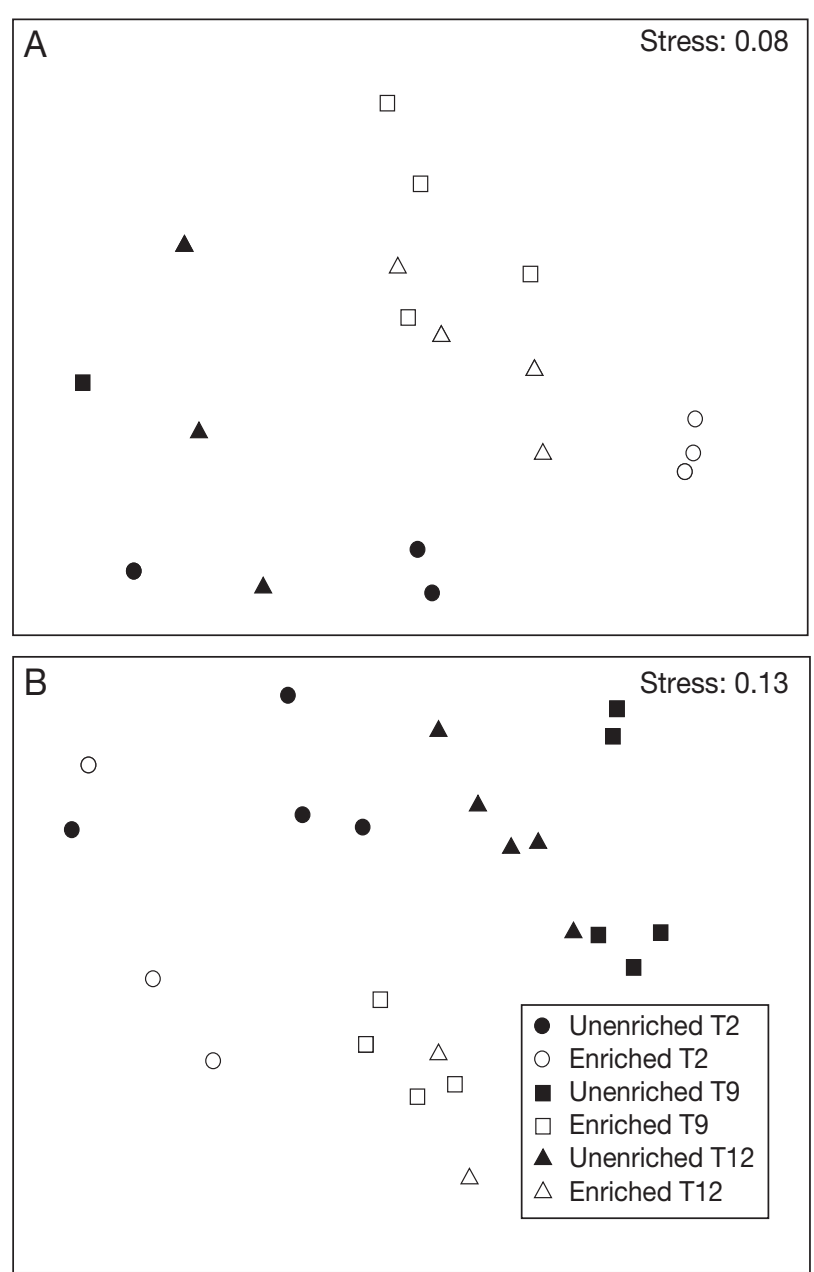

Fig. 3. Two-dimensional nMDS plot of enriched and unenriched site Flavobacteria community data (A) from Farm 2, production cycle $1, \mathrm{n}=6$, and (B) from production cycle $2, \mathrm{n}=$ 6. (A) $\mathrm{T} 2=2 \mathrm{mo}, \mathrm{T} 9=9 \mathrm{mo}, \mathrm{T} 12=12 \mathrm{mo}$; (B) $\mathrm{T} 2=12 \mathrm{mo}$, $\mathrm{T} 9=21 \mathrm{mo}, \mathrm{T} 12=24 \mathrm{mo}$

both unenriched and enriched sites had shifted (but in different directions) and had become different. After the fallowing period, the communities had shifted again to become more similar. Although the significance value of $p=0.05$ suggests that the groups were not different, the R-value of 0.782 indicates otherwise. Given the low number of permutations and the MDS plot it appears most likely that although the Flavobacteria communities at the end of the cycle had shifted to become more similar, they still remained markedly different and were different from their initial states.

\section{Community diversity (richness)}

Community diversity (richness) was assessed as changes in the average number of bands per lane on DGGE gels. Despite some variation in the average 
number of bands per lane at each sampling time, enriched sites often possessed more, but never fewer, bands than unenriched sites (Table 2). The total number of bands observed over the 2 yr trial at Farms 1 and 2 was high (29 and 31, respectively) and indicated diverse Flavobacteria communities.

\section{Flavobacterial concentrations}

We used QPCR to determine the number of copies of Flavobacteria and total bacterial 16S rRNA genes in enriched and unenriched sediment samples. Throughout the text, we refer to flavobacterial and total bacterial numbers as the number of $16 \mathrm{~S}$ rRNA genes detected by the primer sets we employed. Although the primer set gives several mis-hits to phylotypes outside those targeted, it should be noted that all bands sequenced from DGGE gels fell within the target group, indicating that the primers employed did

Table 2. Average DGGE bands per gel for sites at Farm 1 and Farm 2, over the 2 yr trial. Total unique bands were 29 for Farm 1 and 31 for Farm 2. Numbers in parentheses refer to enriched and unenriched sites 1 and 2, respectively. T2: 2 mo; T9: 9 mo; T1: $12 \mathrm{mo}$

\begin{tabular}{|c|c|c|c|c|}
\hline \multirow{2}{*}{ Time } & \multicolumn{2}{|c|}{$\longrightarrow$ Farm $1 \longrightarrow$} & \multicolumn{2}{|c|}{ - Farm 2} \\
\hline & Enriched & Unenriched & Enriched & Unenriched \\
\hline \multicolumn{5}{|c|}{ Production cycle 1} \\
\hline $\mathrm{T} 2$ & $15 \pm 2$ & $13 \pm 2$ & $22 \pm 1$ & $6 \pm 3$ \\
\hline T9 & $14 \pm 0$ & $12 \pm 1$ & $9 \pm 2$ & $2 \pm 0$ \\
\hline T12 & $11 \pm 2$ & $6 \pm 0$ & $11 \pm 2$ & $4 \pm 1$ \\
\hline \multicolumn{5}{|c|}{ Production cycle 2} \\
\hline $\mathrm{T} 2$ & $\begin{array}{l}\text { (1) } 11 \pm 2 \\
\text { (2) } 10 \pm 1\end{array}$ & $\begin{array}{l}\text { (1) } 6 \pm 0 \\
\text { (2) } 12 \pm 4\end{array}$ & $4 \pm 1$ & $4 \pm 1$ \\
\hline T9 & $\begin{array}{l}\text { (1) } 14 \pm 0 \\
\text { (2) } 17 \pm 2\end{array}$ & $\begin{array}{l}\text { (1) } 7 \pm 0 \\
\text { (2) } 10 \pm 2\end{array}$ & $17 \pm 3$ & $10 \pm 1$ \\
\hline T12 & $\begin{array}{l}\text { (1) } 16 \pm 0 \\
\text { (2) } 15 \pm 2\end{array}$ & $\begin{array}{l}\text { (1) } 9 \pm 0 \\
\text { (2) } 10 \pm 0\end{array}$ & $13 \pm 0$ & $9 \pm 1$ \\
\hline
\end{tabular}

indeed target many of the dominant Flavobacteria in these sediments. Although our counts are subject to uncertainties at several stages of the QPCR process (DNA extraction, PCR, analysis) total bacterial counts are in good agreement to those we reported previously (Bissett et al. 2007) as direct counts. Although the absolute numbers are slightly different, the same trends are clear, and at a minimum our QPCR represent good relative counts.

At Farm 1 during the first $12 \mathrm{mo}$, the flavobacterial numbers were higher in enriched site sediments throughout the 12 mo period. Furthermore, flavobacterial numbers also increased over the stocking period and declined during the fallowing period. Together, these results indicate that both treatment $\left(F_{1,32}=100\right.$, $\mathrm{p}<0.001)$ and time $\left(F_{2,32}=8.0, \mathrm{p}=0.002\right)$ had significant effects. Flavobacterial numbers increased most markedly at the enriched sites during the 9 mo stocked period (Table 3).

During the second 12 mo at Enriched 1/Unenriched 1, both treatment $\left(F_{1,18}=125, \mathrm{p}<0.0001\right)$ and time $\left(F_{2,18}=\right.$ $17, \mathrm{p}<0.0001)$ had a significant effect on flavobacterial numbers; at Enriched 2/Unenriched 2 only treatment $\left(F_{1,16}=48, \mathrm{p}<0.0001\right)$ affected the size of the flavobacterial population. At both pairs of sites, the flavobacterial population was larger at the enriched site, but did increase at both enriched and unenriched sites during the 9 mo stocking period and then declined during the 3 mo fallowing period (Table 3 ).

During the first 12 mo at Farm 2, flavobacterial numbers were affected by treatment $\left(F_{1,27}=14, \mathrm{p}=0.001\right)$, but not by time. The numbers of Flavobacteria were significantly higher $(p<0.05)$ at enriched sites than at unenriched sites, where numbers remained stable throughout the first 12 mo (Table 3). During the second 12 mo at Farm 2, both treatment $\left(F_{1,27}=5.6, \mathrm{p}=0.028\right)$ and time $\left(F_{2,27}=4.3, \mathrm{p}=0.027\right)$ had significant effects on the sediment flavobacterial numbers. The numbers of Flavobacteria were higher at the enriched sites and

Table 3. Flavobacterial 16S rRNA gene copy number $\left(\times 10^{7}\right)$ per $g$ sediment and \% of total bacterial population at Farm 1 (mean \pm $\mathrm{SE}, \mathrm{n}=6$ for Year 1 and $\mathrm{n}=3$ for Year 2) and at Farm 2 (mean $\pm \mathrm{SE}, \mathrm{n}=3$ ) during the $2 \mathrm{yr}$ trial. T2: 2 mo; T9: 9 mo; T12: 12 mo

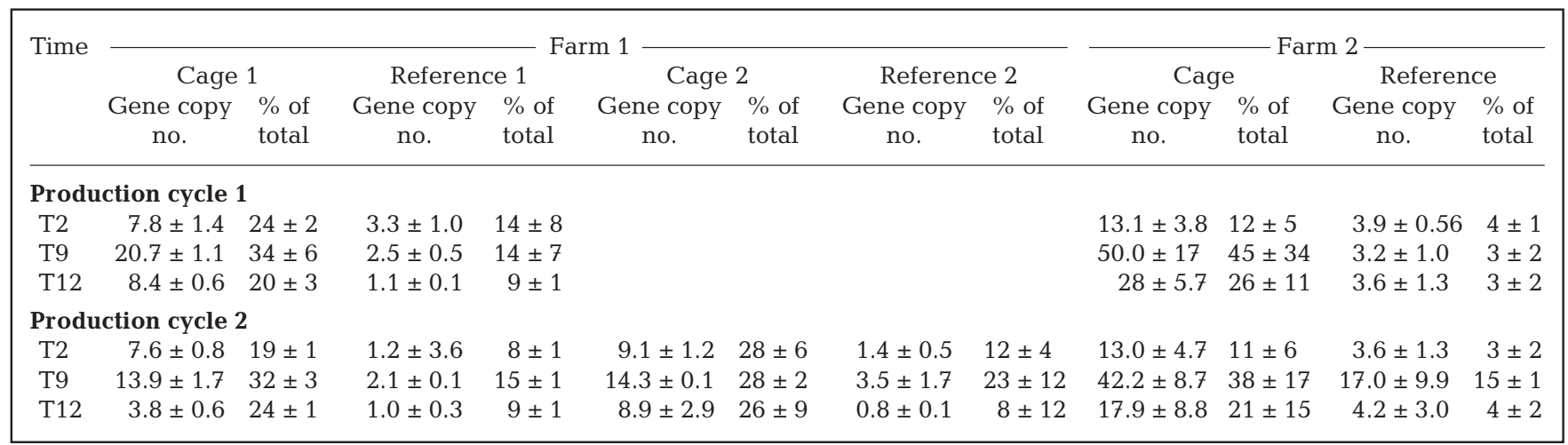


increased over the 9 mo stocking period followed by a decline over the 3 mo fallowing period (Table 3 ). All of these trends were also observed when flavobacterial numbers were considered as a percentage of total DNA, as determined by real-time PCR with universal primers (Table 3).

\section{Sequences from DGGE gels}

Bands were sequenced randomly from gels to assess the validity of the assumptions of DGGE (i.e. that a unique band represents a unique phylotype) and the fidelity of the primer set used. All bands excised and sequenced from DGGE gels were found to fall within the class Flavobacteria (Fig. 4). Most of the sequences found in sediments associated with Farm 1 and Farm 2 were more closely related to gene sequences from uncultured organisms than to sequences from cultivated species. The sequences found in this study grouped with environmental sequences found in a variety of marine ecosystems, including marine sediments. Also of interest is the fact that several of the band sequences from both farms grouped closely with clones found in the same sediments in another study investigating total bacterial diversity (Bissett et al. 2006; labelled Nubeena and Dover in our Fig. 4), suggesting that they comprised a significant part of the community and that the primer set used (558f and 1392rc) was effective in amplifying the targeted bacterial species. No bands were found to be unique to only enriched or unenriched sites, and no bands were present throughout all samples.

\section{DISCUSSION}

We investigated shifts in the Flavobacteria communities in organically enriched and unenriched sediments. We assessed shifts in the sediment Flavobacteria communities induced by organic pollution and then followed further community changes as sediments were allowed to recover. The PCR primers successfully amplified partial 16S rRNA gene fragments from class Flavobacteria bacteria. Although the actual Flavobacteria population (in terms of both diversity and density) may have been underestimated (Kirchman 2002), the diversity exhibited by these sequences suggests that the primers did cover much of the target group population from these sediments.

At both farms, Flavobacteria communities at enriched and unenriched sites were significantly different from one another at all but 1 sampling time. At the end of the first fallowing period/beginning of the second stocking period at Farm 2, the Flavobacteria communities in the enriched sediment were the same as the communities in the unenriched site sediment (Table 1). During the second farm cycle, this time point is actually a true 'time zero' showing the similarity of the unenriched and enriched sites, as opposed to the 2 mo sampling at the beginning of the first cycle. Despite the rapid shifts in the community after the beginning of the organic loading, the general response of the 2 farms was remarkably similar. Rosselló-Mora et al. (1999) reported a rapid increase in carbon mineralisation rates and in microbial numbers after the addition of organic matter to sediment microbial communities. They also attributed much of this response to the Flavobacteria. All sites at both farms showed much within-treatment variation in Flavobacteria community structure over time, to the extent that the unenriched site communities also changed significantly between sampling times (Figs. 1, $3 \& 4$ ). This variation was often difficult to separate from the effects of organic loading, and was clear from the significant interaction terms in the statistical results. The fact that these terms were often significant highlights the complex nature of community level changes in highly diverse communities, and the importance of attempting to partition as much variance as possible when designing in situ ecological studies and analysing the data sets produced by these investigations. The effects of temperature on microbial communities and microbial production are well known (Rosselló-Mora et al. 1999) and the seasonal variation exhibited in these sediments is not unusual, but does make the interpretation of the organic enrichment effect more difficult. Despite the noise created by the large natural variation, it is clear that the Flavobacteria communities in these sediments shift in response to organic loading.

Flavobacteria numbers at both farms (as measured by real-time PCR targeting flavobacterial rRNA genes) increased with stocking and decreased with fallowing at all enriched sites. This was true for both absolute amounts of Flavobacteria and when their number was considered as a proportion of the total bacterial community, indicating that the increase in flavobacterial DNA was not simply a result of a general increase in all bacteria with farming. Bissett et al. (2007) reported SYBR green direct bacterial counts for the same sediment samples. Their results showed the same trend as those revealed by our QPCR results for the total community. That is, direct counts showed that bacterial numbers increased significantly with organic loading and decreased with its cessation. The fact that Flavobacteria increased in relation to the rest of the community with loading and decreased after its cessation suggests their importance in the initial processing of organic matter. Other studies (Rosselló-Mora et al. 1999, Kirchman 2002, Cytryn et al. 2003) have also 
Cytophaga fermentans (D12661)

- Uncultured marine sediment bacterium (DQ334631)

— Uncultured Bacteroidetes bacterium (EU052254)

Farm 2 B62

(AY167327)

Tenacibaculum sp. HJ103 (DQ660385)
Farm 1, B38

_ Marine Flavobacteriaceae bacterium SA-0082 (AB057592)

arm 2 B68

- Uncultured diatom bloom bacterium (DQ372851)

Uncultured bacterioplankton Bacteroidetes bacterium (EF016467)

Farm 2 B69

Uncultured Bacteroidetes clone Nubeena281 (AY500036)

L Farm 2 B52

Lutibacter litoralis (AY962293)

Sea ice Sphingobacteriales bacterium gap-f-48 (DQ530470)

Uncultured sediment Cytophagales bacterium (AJ535257)

Croceimarina litoralis (EF108214)

Uncultured hydrothermal vent Bacteroidetes bacterium (AY327884)

Farm 2 B55

- Uncultured marine sediment Bacteroidetes bacterium (AY678510)

Lutimonas vermicola (EF108218)

Uncultured sponge Flavobacterium sp. (AM259872)

Uncultured Bacteroidetes clone Dover121 (AY499782)

Uncultured mud volcano Bacteroidetes bacterium (AJ704703)

Farm 2 B73

Farm 2 B65

Actibacter sediminis (EF670651)

- Uncultured whalefall Bacteroidetes bacterium(AY922244)

- Uncultured sediment Bacteroidetes bacterium (DQ351766)

L Farm 1 B33

- Farm 2 B58

- Uncultured hydrothermal sediment bacterium (DQ832632)

Uncultured hydrothermal sediment bacterium (DQ832639)

- Farm 2 B67

- Uncultured sulfidic cave bacterium (EF467458)

Uncultured hydrothermal vent bacterium (AF419681)

Farm 2 B56

Uncultured sulfide microbial incubator bacterium (DQ228644)

- Farm 1 B27

Uncultured marine plankton Flavobacteria bacterium (AM279180)

Uncultured marine Flavobacteria bacterium (EF202336)

Uncultured marine bacterium (EF572248)

Gaetbulibacter saemankumensis (AY883937)

Flavobacteriaceae bacterium DOKDO 020 (DQ191181)

Farm1 B44

Farm 2 B47

L Farm 1 B8

- Flavobacterium sp. 5N-3 (AB017597)

- Marine Flavobacteriaceae bacterium LPK5 (EF527871)

- Marine sediment Flavobacterium sp. 3034 (AM110988)

Uncultured sediment Cytophaga sp. (AB015545)

- Uncultured hydrothermal ridge bacterium (DQ832635) Farm1 B23

Psychroserpens sp. A622 (AY781191)

Bacteroidetes sponge bacterium R8-Ret-T12-11d (AM117935)

Lacinutrix copepodicola (AB261015)

Farm 2 B46

L Farm 2 B51

Mesoflavibacter zeaxanthinifaciens (AB265181)

Formosa sp. 5IX/A01/134 (AY576730)

- Bizionia palithoae (DQ462579)

- Psychroserpens sp. ARK10236 (AY167341)

- Uncultured cold seep sediment Cytophaga sp. (AB015262)

Uncultured Bacteroidetes bacterium Nubeena136 (AY500047)

Psychroserpens burtonensis (U62913)

Uncultured sediment Cytophagales bacterium (AM040138)

Bizionia myxarmorum (AY694002)

- Uncultured Bacteroidetes bacterium Nubeena333 (AY500040)

- Subsaximicrobium saxinquilinus (AY693998)

- Uncultured marine bacterium (DQ009101)

- Uncultured marine plankton Flavobacteria bacterium (AM279174)

4 - Marine sponge Flavobacteriaceae bacterium TJD809 (DQ993346)

- Marine Flavobacteriaceae bacterium SW325 (AF493690)

Farm 2 B70

L Farm 2 B53

Farm1 B28

Gelidibacter mesophilus (AJ344133)

Uncultured soil Cellulophaga sp. (AY794193)

- Uncultured soil Bacteroidetes bacterium (AY794203)

- Farm 1 B37

Uncultured marine bacterium (DQ906733) Ivibacter sp. AKS476 (DQ660381)

Dokdonia donghaensis MED134 (AAMZ01000009)

Krokinobacter genikus (AB198085)

Krokinobacter eikastus (AB198088)

Fig. 4 (continued on next page) 


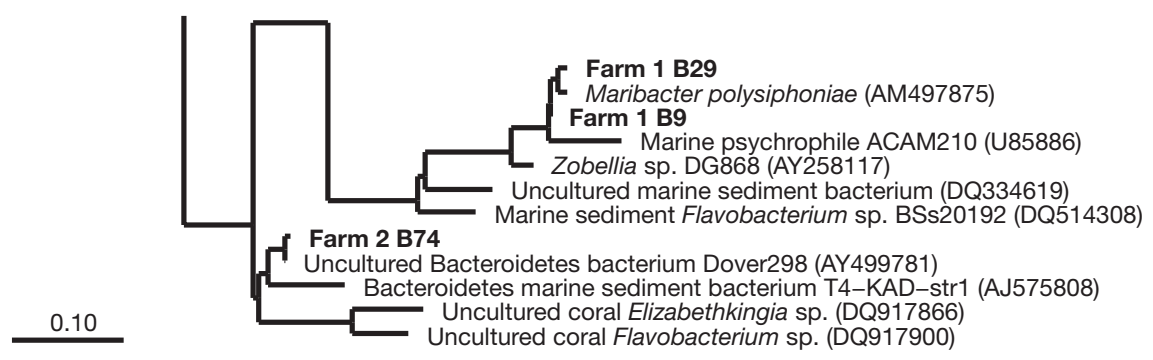

Fig. 4. (continued) Similarity tree showing the phylogenetic affiliations of 16S rRNA sequences obtained from bands excised from the DGGE gels. The tree was constructed with the software package ARB, based on full-length sequences, using parsimony analysis. The partial DGGE band sequences (bold) were inserted into the tree by using maximum-parsimony criteria without affecting the initial tree topology, using a special tool implemented in ARB. Numbers in parentheses are accession numbers. Scale bar $=10 \%$ sequence divergence

shown Flavobacteria numbers to increase with organic loading. These studies have also suggested that the Flavobacteria may play a key role in the initial degradation of complex organic substrates, supplying hydrolysis and fermentation products for further mineralisation.

Other benthic parameters (infauna, redox, sulphide, dissolved oxygen) measured in parallel studies (Macleod et al. 2004a) exhibited different but predictable responses to organic loading. For instance, the depth of the oxic zone decreased markedly (Bissett et al. 2007) while sulphide concentration increased (Macleod et al. 2004a) with organic loading. The increase in flavobacterial numbers during loading (also inferred by Bissett et al. 2007) suggests that the Flavobacteria were able to adapt well to conditions under organic loading, further supporting the notion that these bacteria are important in organic matter remineralisation, even in anaerobic sediments. Although we have not directly assessed the role of the Flavobacteria in degradation or in stimulating benthic production, it is possible that they play an important role as initial biopolymer degraders in the investigated sediments. The importance of the Flavobacteria in performing this initial degradation step in sediments receiving large amounts of anthropogenic organic input deserves further investigation.

All sequences acquired from excised DGGE bands grouped with flavobacterial sequences from a wide range of benthic and pelagic environments (Fig. 4). These include Antarctic sediments, anaerobic sulphate-reducing sediments, marine plankton and sediments impacted by hydrocarbon spills. Many of the band sequences also grouped closely with sequences found in clone libraries from these sediments (AY499781-2, AY500036, AY500040 and AY500047; Bissett et al. 2006). The Flavobacteria communities at both Farm 1 and Farm 2 are diverse and appear to overlap considerably. The overlap in Flavobacteria phylotypes at both farms is discernable by the large phylogenetic diversity of sequences from both Farm 1 and Farm 2 throughout the entire similarity tree shown in Fig. 4. Previous studies have shown that nutrient enrichment may lead to a decrease in total microbial diversity (e.g. Torsvik et al. 1998). This reduction of diversity may occur as fewer microbes are able to flourish in the often more heterogeneous and extreme, pollution-induced environment. However, the effect of organic pollution specifically on flavobacterial populations is unknown. Diversity (richness) analysis based on DGGE band number quantification showed that enriched sites were at least as diverse as unenriched sites. It should be noted that diversity is difficult to assess using this method. Diversity comprises both richness and evenness, with only the former being assessed here. It is possible that apparent changes in richness may really be changes in the evenness of the communities. The absence of bands does not necessarily imply that the organisms responsible for them are absent from the sample, but that their numbers merely fall below the detection limit. The fact that enriched sites appear more diverse may really reflect a higher evenness (which we did not assess). Therefore we expect that in reality some phylotypes are induced by organic loading and some are suppressed by it. What is clear, however, is that the organic loading does not result in a drastic reduction of flavobacterial diversity. Both the enriched and unenriched sediments investigated herein were continually changing (e.g. by bioturbation, mixing caused by storm events, seasonal changes), and although there is a clear effect of organic loading on the enriched sediments, this effect does not explain the inherent, non-predictable, dynamism in flavobacterial communities at both enriched and unenriched sites. Although we have not directly investigated the specific function of Flavobacterial phylotypes in these sediments, it seems likely that high functional redun- 
dancy together with random colonisation processes in response to environmental variability strongly influence the composition of the flavobacterial communities in these sediments.

The results presented here indicate that the input of readily degradable organic carbon is one of a number of factors that influence Flavobacteria community composition, and that the availability of organic matter is a major determinant of Flavobacteria density. Flavobacteria communities at both enriched and unenriched sites displayed variation that may be attributed to natural temporal variation, and differences between unenriched sites at both locations may be attributed to the different sediment types sampled. Bacterial numbers were higher in the sediments of Farm 2, which also had a higher carbon content. However, the direct influence of organic loading was clearly detectable at enriched sites throughout the trial. The Flavobacteria communities at both sites appeared to be diverse and resilient to organic loading. In fact, because of the positive response of the Flavobacteria to organic pollution, it is possible that these bacteria play a fundamental role in the initial polymer degradation of organic matter and are important determinants of the system's assimilative capacity.

Acknowledgements. This work formed part of a project of Aquafin CRC and received funds from the Australian Government's CRCs Program, the Fisheries R\&D Corporation and other CRC Participants. This study could not have been completed without the assistance of the Aquafin CRC fallowing group (particularly Catriona Macleod, Susan Forbes, Danny Holdsworth, and Robert Connell) whose assistance with field sampling was invaluable. We also thank Alban Ramette for helpful comments on earlier drafts of this manuscript.

\section{LITERATURE CITED}

Abell GCJ, Bowman JP (2005a) Colonization and community dynamics of class Flavobacteria on diatom detritus in experimental mesocosms based on Southern Ocean seawater. FEMS Microbiol Ecol 53:379-391

Abell GCJ, Bowman JP (2005b) Ecological and biogeographic relationships of class Flavobacteria in the Southern Ocean. FEMS Microbiol Ecol 51:265-277

Altschul SF, Madden TL, Schäffer AA, Zhang J, Zhang Z, Miller W, Lipman DJ (1997) Gapped BLAST and PSIBLAST: a new generation of protein database search programs. Nucleic Acids Res 25:3389-3402

Anderson MJ (2003a) CAP: a FORTRAN computer program for canonical analysis of principle coordinates. Department of Statistics, University of Auckland

Anderson MJ (2003b) DISTLM v.2: a FORTRAN computer program to calculate a distance-based multivariate analysis for a linear model. Department of Statistics, University of Auckland

Anderson MJ (2003c) NPMANOVA: a FORTRAN computer program for non-parametric multivariate analysis of variance (for any two factor design) using permutation tests. Department of Statistics, University of Auckland
Anderson MJ (2003d) XMATRIX: a FORTRAN computer program for calculating design matrices for terms in ANOVA designs in a linear model. Department of Statistics, University of Auckland

Battersby NS, Brown CM (1982) Microbial activity in organically enriched marine sediments. In: Nedwell DB, Brown CM (eds) Sediment microbiology. Academic Press, London, p 147-170

Bernardet JF, Nakagawa Y (2006) An introduction to the family Flavobacteriaceae. In: Dworkin M, Falkow S, Rosenberg E, Schleifer KH, Stackebrandt E (eds) The prokaryotes, Vol 7. Springer-Verlag, New York, p 455-480

Bissett A, Bowman J, Burke C (2006) Bacterial diversity in organically-enriched fish farm sediments. FEMS Microbiol Ecol 55:48-56

Bissett A, Burke C, Bowman JP, Cook PLM (2007) Bacterial community shifts in organically perturbed sediments. Environ Microbiol 9:46-60

Clarke KR, Warwick RM (2001) Change in marine communities: an approach to statistical analysis and interpretation, 2nd edn. PRIMER-E, Plymouth

Cloern JE (2001) Our evolving conceptual model of the coastal eutrophication problem. Mar Ecol Prog Ser 210:223-253

Cottrell MT, Kirchman DL (2000) Natural assemblages of marine Proteobacteria and members of the CytophagaFlavobacter cluster consuming low- and high-molecularweight dissolved organic matter. Appl Environ Microbiol 66:1692-1697

> Covert JS, Moran MA (2001) Molecular characterization of estuarine bacterial communities that use high- and lowmolecular weight fractions of dissolved organic carbon. Aquat Microb Ecol 25:127-139

Cytryn E, Gelfand I, Barak Y, van Rijn J, Minz D (2003) Diversity of microbial communities correlated to physiochemical parameters in a digestion basin of a zero-discharge mariculture system. Environ Microbiol 5: 55-63

Ferris MJ, Muyzer G, Ward D (1996) Denaturing gradient gel electrophoresis profiles of 16S rRNA-defined populations inhabiting a hot spring microbial mat community. Appl Environ Microbiol 62:340-346

Hall TA (1999) BioEdit: a user-friendly biological sequence alignment editor and analysis program for Windows 95/98/NT. Nucleic Acids Symp Ser 41:95-98

Kirchman DL (2002) The ecology of Cytophaga-Flavobacteria in aquatic environments. FEMS Microbiol Ecol 39:91-100

Lane DJ (1991) 16S/23S rRNA sequencing. In: Stackbrandt E, Goodfellow M (eds) Nucleic acid techniques in bacterial systematics. John Wiley \& Sons, New York, p 115-175

Legendre P, Anderson MJ (1999) Distance-based redundancy analysis: testing multispecies responses in multifactorial ecological experiments. Ecol Monogr 69:1-24

Llobet-Brossa E, Rosselló-Mora R, Amann R (1998) Microbial community composition of Wadden Sea sediments as revealed by fluorescence in situ hybridization. Appl Environ Microbiol 64:2691-2696

Ludwig W, Strunk O, Klugbauer S, Klugbauer N and others (1998) Bacterial phylogeny based on comparative sequence analysis. Electrophoresis 19:554-568

Macleod CK, Crawford CM, Moltschaniwskyj NA (2004a) Assessment of long term change in sediment condition after organic enrichment: defining recovery. Mar Pollut Bull 49:79-88

Macleod CKA, Bissett A, Burke C, Forbes S and others (2004b) Novel methods for the assessment of sediment condition and determination of management protocols for sustainable finfish cage aquaculture operations. Aquafin CRC, Adelaide, SA 
Paerl HW (1998) Structure and function of anthropogenically altered microbial communities in coastal waters. Curr Opin Microbiol 1:296-302

Paerl HW, Dyble J, Maoisander PH, Noble RT and others (2003) Microbial indicators of aquatic ecosystem change: current applications to eutrophication studies. FEMS Microbiol Ecol 46:233-246

Pearson TH, Rosenberg R (1978) Macrobenthic succession in relation to organic enrichment and pollution of the marine environment. Oceanogr Mar Biol Annu Rev 16:229-311

Pruesse E, Quast C, Knittel K, Fuchs BM, Ludwig W, Peplies J, Glockner FO (2007) SILVA: a comprehensive online resource for quality checked and aligned ribosomal RNA sequence data compatible with ARB. Nucleic Acids Res 35:7188-7196

Ravenschlag K, Sahm K, Amann R (2001) Quantitative molecular analysis of the microbial community in marine Arctic sediments (Svalbard). Appl Environ Microbiol 67:387-395

Reichenbach H, Dworkin M (1991) The order Cytophagales. In: Balows A, Truper HG, Dworkin M, Harder W, Schleifer $\mathrm{KH}$ (eds) The prokaryotes. Springer-Verlag, New York, p 356-379

Editorial responsibility: Rutger De Wit, Montpellier, France
Rosselló-Mora R, Thamdrup B, Schäfer H, Weller R, Amann R (1999) The response of the microbial community of marine sediments to organic carbon input under anaerobic conditions. Syst Appl Microbiol 22:237-248

Thompson JD, Higgins DG, Gibson TJ (1994) CLUSTAL W: improving the sensitivity of progressive multiple sequence alignment through sequence weighting, positions-specific gap penalties and weight matrix choice. Nucleic Acids Res 22:4673-4680

Torsvik V, Daae F, Sandaa RA, Ovreas L (1998) Novel techniques for analysing microbial diversity in natural and perturbed environments. J Biotechnol 64:53-62

Wardle DA, Giller KE (1996) The quest for a contemporary ecological dimension to soil biology. Soil Biol Biochem 28:1549-1554

Weller R, Glöckner FO, Amann R (2000) 6S rRNA-trageted oligonucleotide probes for the in situ detection of members of the phylum Cytophaga-Flavobacterium-Bacteroidetes. Syst Appl Microbiol 23:107-114

Zak JC, Willig MR, Moorhead DL, Wildman HG (1994) Functional diversity of microbial communities: a quantitative approach. Soil Biol Biochem 26:1101-1108

Submitted: June 25, 2007; Accepted: December 13, 2007 Proofs received from author(s): March 27, 2008 